\title{
Lokalizacja imperfekcji w płycie betonowej za pomocą metody tomografii ultradźwiękowej
}

\author{
Localization of the imperfections in the concrete slab \\ using ultrasonic tomography
}

\section{Streszczenie}

W artykule przedstawiono zastosowanie tomografu ultradźwiękowego do lokalizacji imperfekcji w płycie betonowej dostępnej jednostronnie. Wykorzystano w tym celu opracowaną metodykę nieniszczącego badania elementów z betonu z wykorzystaniem najnowszej nieniszczącej metody akustycznej tomografii ultradźwiękowej. Badania przeprowadzono na obiekcie rzeczywistym będącym w trakcie remontu. Do badań wytypowano obszar, co do którego zachodziło podejrzenie występowania imperfekcji materiałowej, ponieważ w trakcie wiązania betonu obszar ten został zalany przez wodę opadową. Wykonano badania nieniszczące $z$ wykorzystaniem tomografu ultradźwiękowego, na podstawie których zlokalizowano miejsce występowania imperfekcji materiałowej.

Słowa kluczowe: beton, badania nieniszczące, tomograf ultradźwiękowy

\section{Abstract}

The article describes the use of an ultrasound tomography to locate the place of imperfections in the concrete slab. For this purpose developed methodology for non-destructive testing of concrete elements using the latest non-destructive method of acoustic ultrasonic tomography was used and study was conducted on a real object which is under renovation. The test site, on which occurred the suspicion of imperfection, because during concrete bonding area was flooded by rainwater. Nondestructive testing was performed using an ultrasonic tomography, on the basis of which localized the place of material imperfection.

Keywords: concrete, nondestructive evaluation, ultrasonic tomography

\section{Wstęp}

W trakcie realizacji inwestycji budowlanych związanych z układaniem betonu dochodzi czasem do sytuacji, w wyniku których elementy konstrukcyjne wykonane z tego materiału ulegają uszkodzeniu. Dzieje się tak na przykład, kiedy w trakcie betonowania następuje nagła zmiana pogody, a intensywne opady deszczu oddziaływują bezpośrednio na "świeżo" ułożony beton. Wymaga to wówczas oceny stanu technicznego takiego elementu konstrukcyjnego w celu sprawdzenia, czy stany graniczne są nadal spełnione [1]. Taka sytuacja miała miejsce na jednej z budów. Inwestor zaniepokojony stanem betonu, z którego wykonano płytę betonową, zlecił wykonanie badań. Celem badań było stwierdzenie aktualnego stanu technicznego betonu w obszarze, co do którego zachodziło podejrzenie występowania imperfekcji materiałowej.

W artykule przedstawiono możliwość lokalizacji miejsca występowania imperfekcji materiałowej w płycie betonowej dostępnej jednostronnie za pomocą tomografu ultradźwiękowego wykorzystującego fale poprzeczne.

\section{Badania nieniszczące z wykorzystaniem tomografu ultradźwiękowego}

Metoda tomografii ultradźwiękowej bazuje na wzbudzeniu fali sprężystej w badanym elemencie. Wzbudnikiem jest wielogłowicowa antena, posiadająca wbudowanych kilkadziesiąt zintegrowanych głowic ultradźwiękowych, która służy również do odbierania i przetwarzania sygnałów ultradźwiękowych. Jest to nowa metoda opisana głównie w publikacjach [2:9]. Głowice generują impulsy ultradźwiękowe o częstotliwości $50 \mathrm{kHz}$. Maksymalny zasięg, w rozumieniu grubości badanego elementu wynosi do $2500 \mathrm{~mm}$.

Tomograf jest przystosowany do badania elementów z betonu $\mathrm{w}$ celu określenia wielkości i lokalizacji imperfekcji w elementach betonowych dostępnych jednostronnie, wykrywania pęknięć, wtrąceń, pustek powietrznych i innych miejsc, które mogą być albo puste albo wypełnione cieczą lub materiałem różniącym się gęstością i innymi fizycznymi mechanicznymi własnościami od otaczającego go betonu, a także do oceny grubości takich elementów.

Na rysunku 1 przedstawiono konstrukcję tomografu ultradźwiękowego i podano nazwy trzech wzajemnie prostopadłych względem siebie przekrojów badanego obiektu (tzw. skanów) wraz z układem współrzędnych związany z anteną tomografu [3]. W jego skład wchodzi wielogłowicowa antena ultradźwiękowa i zintegrowany komputer wraz ze specjalistycznym oprogramowaniem umożliwiającym zapis graficznego obrazu.

$\mathrm{Na}$ uwage zasługuje fakt, że każda głowica została zamontowana w antenie oddzielnie teleskopowo i dzięki zastosowaniu techniki DPC (dry point contact) nie wymaga stosowania środka sprzęgającego i specjalnego przygotowania powierzchni do badania, bo dopasowuje się do niej. Odległości między głowicami wynoszą $30 \mathrm{~mm}$ w pionie i $40 \mathrm{~mm}$

Dr hab. inż. Krzysztof Schabowicz - Wydział Budownictwa Lądowego i Wodnego, Politechnika Wrocławska. 

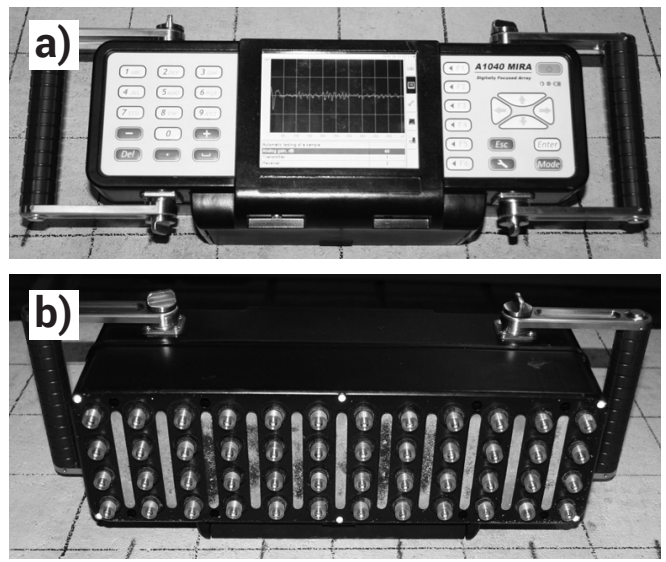
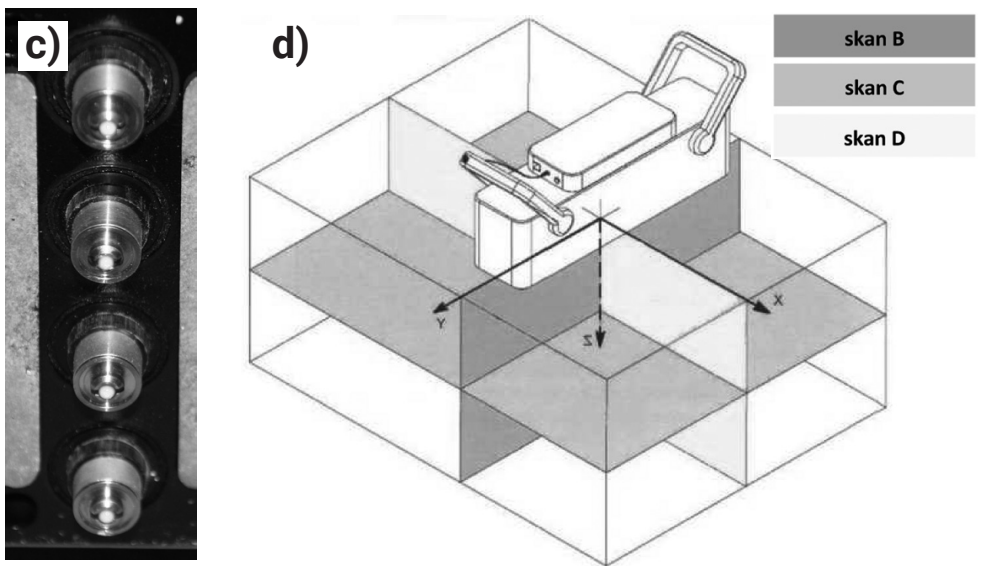

Rys. 1. Widok tomografu ultradźwiękowego: a) od góry, b) od dołu, c) zbliżenie pojedynczej głowicy, d) nazwy trzech wzajemnie prostopadłych względem siebie przekrojów badanego obiektu (tzw. skanów) i układ współrzędnych związany z anteną tomografu [3]

Fig. 1. View of the ultrasonic tomography: a) from above, b) from below, c) drawing of a single head, d) the names of three mutually orthogonal to each cross-section of the object (ie. scans) and the coordinate system associated with the antenna [3]

w poziomie. W przypadku dużych imperfekcji podane odległościmiędzy głowicami nie mają większego znaczenia, natomiast w przypadku małych imperfekcji mogą z tego powodu występować niedokładności w identyfikacji wielkości tej imperfekcji.

\section{Badania płyty betonowej}

Do badania płyty betonowej wykorzystano opracowaną metodykę nieniszczącego badania elementów z betonu z zastosowaniem najnowszej nieniszczącej metody akustycznej tomografii ultradźwiękowej [2]. Ukierunkowana została ona na określanie wielkości i lokalizacji imperfekcji w elementach betonowych dostępnych jednostronnie.

I tak, badania z wykorzystaniem tomografu ultradźwiękowego przeprowadzono na fragmencie płyty betonowej o wymiarach $3500 \times 2000 \mathrm{~mm}$, łącznie w siedemenastu pasmach o szerokości około $350 \mathrm{~mm}$ każde. W każdym paśmie wykonano 20 pomiarów. Badany fragment płyty podzielono na osiem obszarów: sześć o wymiarach 1000x1000 mm i dwa o wymiarach $500 \times 500 \mathrm{~mm}$ W trakcie badania podłogi antena tomografu ultradźwiękowego była stale przesuwana w danym paśmie w jednym kierunku, o odległość co $100 \mathrm{~mm}$ z przesunięciem o $200 \mathrm{~mm}$. Łączna liczba miejsc pomiarowych wynosiła około 350 . Obrazy przekrojów w każdym położeniu były gromadzone w tabeli macierzowej trójwymiarowej, a trzy wzajemnie przecinające się przekroje badanego obiektu (skany B, C i D) były wykonywane na bazie tabeli macierzowej. Badaniami objęto obszar płyty betonowej liczący ok. $7 \mathrm{~m}^{2}$.

Na rysunku 2 pokazano widok siatki pomiarowej na całej powierzchni $7 \mathrm{~m}^{2}$ (obszary od T1 do T8) badanej płyty betonowej i przykładowo w obszarze T1.

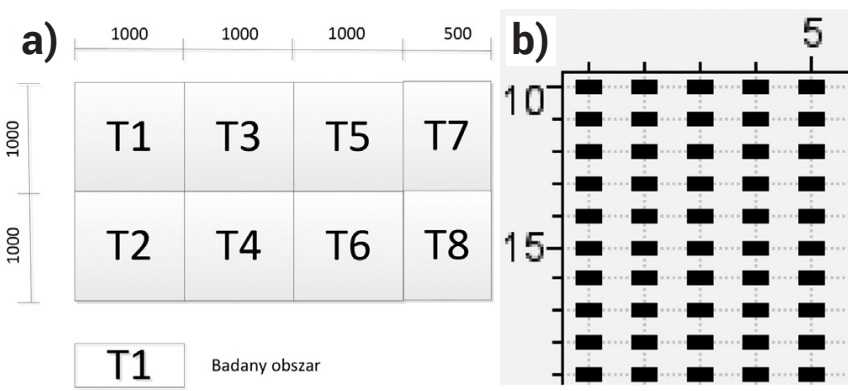

Rys. 2. Widok siatki pomiarowej: a) na badanym tomografem ultradźwiękowym fragmencie płyty betonowej, b) układ punktów pomiarowych przykładowo w obszarze T1

Fig. 2. View of the measurement grid: a) the audited ultrasonic tomography chunk of concrete floors, b) arrangement of measurement points, for example in the area of $\mathrm{T} 1$
Przykładowe wyniki badań nieniszczących otrzymane za pomocą tomografu ultradźwiękowego zamieszczono na rysunkach 3 i 4 pokazujących skany typu C, D i B oraz obraz trójwymiarowy badanego fragmentu płyty betonowej.

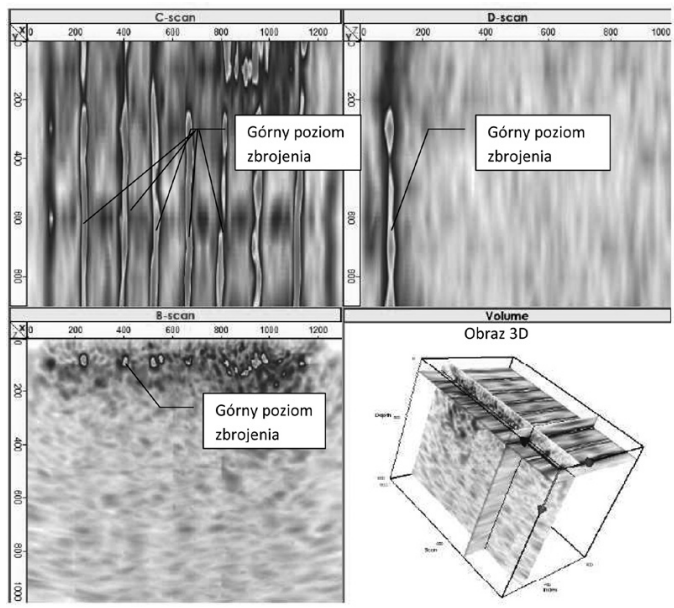

Rys. 3. Skany typu C, D, B i obraz trójwymiarowy badanego fragmentu płyty betonowej, w którym nie stwierdzono imperfekcji (obszar $\mathrm{T} 1$ ) Fig. 3. Scans of type C, D, B and the three-dimensional image of a given segment of the concrete slab, in which no imperfections (area T1)

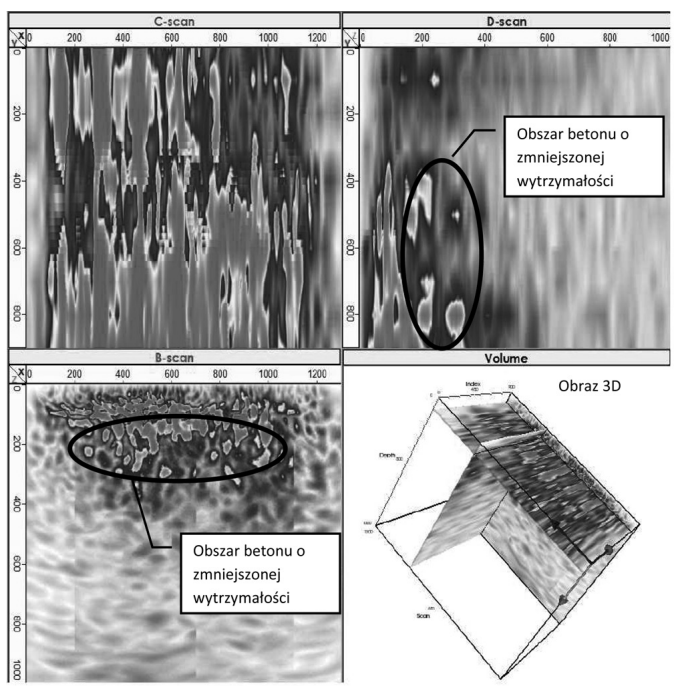

Rys. 4. Skany typu C, D i B oraz obraz trójwymiarowy badanego fragmentu płyty betonowej, w którym stwierdzono imperfekcję materiałową w postaci obszaru o zmniejszonej wytrzymałości (obszar T4) Fig. 4. Scans of type C, D and B and the three-dimensional image of a given segment of the concrete slab, wherein said imperfection material in the form of an area of reduced strength (area T4) 
$\mathrm{Na}$ podstawie analizy poszczególnych skanów stwierdzono, że w obszarze T3 i T4 badanej płyty betonowej wy- stępuje imperfekcja materiałowa w postaci obszaru betonu o zmniejszonej wytrzymałości na ściskanie (rys. 5).

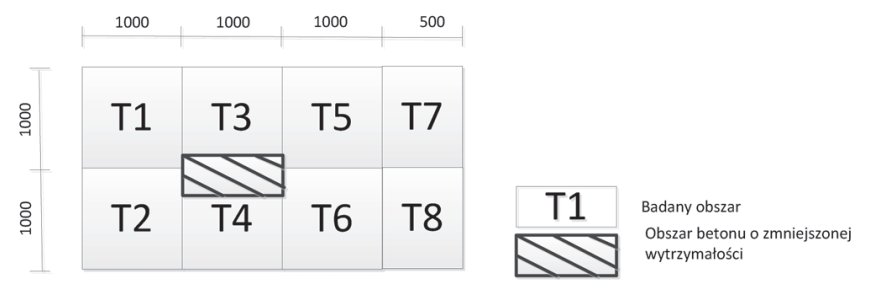

Rys. 5. Widok siatki pomiarowej z zaznaczeniem obszaru betonu o zmniejszonej wytrzymałości na ściskanie

Fig. 5. View the measurement grid indicating a concrete area of reduced compressive strength

\title{
Podsumowanie
}

W artykule przedstawiona została możliwość lokalizacji imperfekcji materiałowej płycie betonowej dostępnej jednostronnie, za pomocą tomografu ultradźwiękowego. Wykonano badania tomografem ultradźwiękowym płyty betonowej, które pozwoliły ustalić obszary betonu o zmniejszonej wytrzymałości na ściskanie. Potwierdzono tym samym możliwość lokalizacji miejsca występowania imperfekcji materiałowych znajdujących się w płycie betonowej dostępnej jednostronnie za pomocą tomografu ultradźwiękowego.

\section{Literatura}

[1] Rozporządzenie Ministra Infrastruktury z dnia 12.04.2002 r. w sprawie warunków technicznych jakim powinny odpowiadać budynki i ich usytuowanie (Dz. U. Nr. 75 poz. 690 z 2002r. z późniejszymi zmianami).

[2] Schabowicz K.: Modern acoustic techniques for testing concrete structures accessible from one side only, Archives of Civil and Mechanical Engineering, DOI: 10.1016/j.acme.2014.10.001.

[3] Schabowicz K.: Ultrasonic tomography - the latest nondestructive technique for testing concrete members - description, test methodology, application example, Archives of Civil and Mechanical Engineering, 2014, Vol. 14, No. 2, 295-303.

[4] Schabowicz K., Suvorov V.: Nondestructive testing of a bottom surface and construction of its profile by ultrasonic tomography, Russian Journal of Nondestructive Testing, 2014, Vol. 50, No. 2, 109-119.

[5] Gorzelańczyk T., Hoła J., Sadowski Ł., Schabowicz K.: Methodology of nondestructive identification of defective concrete zones in unilaterally accessible massive members, Journal of Civil Engineering and Management, 2013, Vol. 19, No. 6, 775-786.
[6] Schabowicz K.: Methodology for non-destructive identification of thickness of unilaterally accessible concrete elements by means of state-of-the-art acoustic techniques, Journal of Civil Engineering and Management , 2013, Vol. 19, No. 3, 325-334.

[7] Schabowicz K., Hoła J.: Nondestructive elastic-wave tests of foundation slab in office building, Materials Transactions, 2012, Vol. 53, 296-302.

[8] Hoła J., Sadowski Ł., Schabowicz K.: Nondestructive identification of delaminations in concrete floor toppings with acoustic methods, Automation in Construction, 2011, Vol. 20,799-807.

[9] Hoła J., Schabowicz K.: State-of-the-art non-destructive methods for diagnostic testing of building structures - anticipated development trends, Archives of Civil and Mechanical Engineering, 2010, Vol. X, $\mathrm{Nr}$ 3, 5-18.

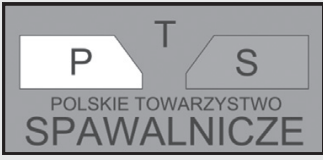

\section{POLSKIE TOWARZYSTWO SPAWALNICZE Oddział w Opolu oraz POLITECHNIKA OPOLSKA}

serdecznie zapraszają do uczestnictwa w:

\section{JUBILEUSZOWEJ, XX NAUKOWO TECHNICZNEJ KONFERENCJI SPAWALNICZEJ „SPAWANIE W ENERGETYCE KONWENCJONALNEJ I JĄDROWEJ"}

\author{
organizowanej w dniach od 19 do 21 kwietnia 2016 r., w Ośrodku „Ziemowit” w Jarnołtówku (Opolskie).
}

\author{
Program ramowy: \\ - sesje referatowe \\ - wystawy techniczne \\ - imprezy towarzyszące
}

Referaty o maksymalnej ilości 8 stron zostaną opublikowane w Przeglądzie Spawalnictwa

i należy je przesłać do 01 lutego 2016 r. na adres jak niżej.

Zainteresowanych udziałem w konferencji zapraszamy

do kontaktowania się z Polskim Towarzystwem Spawalniczym - oddział w Opolu.

Zgłoszenie uczestnictwa w konferencji należy przesłać do 18 marca 2016 r.

Dodatkowe informacje:

Anna Pocica, tel. +48 501598761, e-mail: a.pocica@gmail.com

Tomasz Derwich, tel. +48 77 4019219, e-mail: tomasz.derwich@esab.pl

Zygmunt Bienias, tel +48 502096917

Korespondencję prosimy kierować na adres:

POLSKIE TOWARZYSTWO SPAWALNICZE - ODDZIAE W OPOLU

ul. A. Struga 10, 45-073 OPOLE. (fax: +48 774019201) 